\title{
An Absurd Concept of Self-Medication: A Case of Oral Chemical Burn
}

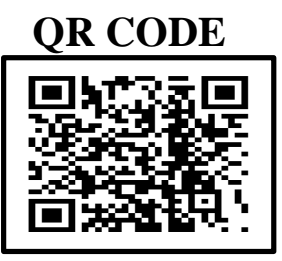

\section{YAGYESHWAR MALHOTRA ${ }^{1}$ PARUL UPPAL MALHOTRA*2, NEERA OHRI ${ }^{3}$, ANINDITA MALLIK ${ }^{4}$}

A chemical burn is seen in oral cavity after a noxious agent is placed in direct contact with the mucosa as a mode of self treatment or iatrogenically by dentist. Mild lesions due to less irritating agents result in mild alteration in texture, while more severe lesions (soreness to outright pain) are due to more irritating agents and because of agents of longer duration of contact. Commonly used chemicals used by patients for tooth pain are aspirin which is placed next to the offending tooth and OTC preparations. The essential oil based preparations are easily available in pharmacies or are prepared by local people. These medicaments can harm a patient if not used under medical or ayurvedic supervision as they have beneficial plant extracts, essential oils etc. A case of such self inflicted chemical burn of the oral mucosa is reported due to use of clove oil preparation available locally, used with varying amount and frequency. History of using over the counter medicaments for dental ailment should be asked when patients visit the dentist with complains of burning or white patch in mouth.

\section{KEYWORDS: Clove oil, Chemical Burn, Trauma}

\section{INTRODUCTION}

Oral chemical burn or ulcers due to the over-thecounter (OTC) medicaments are rare. These lesions resemble different oral lesions. The clinical presentation of these lesion depends on the composition, $\mathrm{pH}$, concentration, quantity, duration, mode of application to tissue, the extent of penetration into tissue, and the mechanism of action. These chemicals can cause diffuse erosive lesions like simple desquamation (mucosal sloughing) or complete mucosal detachment with extension into the submucosa. ${ }^{1}$

Trauma to oral tissues from chemicals poses a diagnostic challenge and hence a detailed history will help to differentiate possible causes of the presenting lesion(s). The clinician should focus on obtaining relevant information from patient should be able to establish a temporal relationship between the usage of OTC preparation and onset of oral lesions. Patient is advised to discontinue medicament application immediately to ensure complete healing. ${ }^{2}$ The clove oil which contains unrefined eugenol has been used for relieving toothache from many decades. Chisholm in 1873 had described its therapeutic usage and formed a plastic mass by mixing it with zinc oxide. Its antibacterial, sedative and anodyne properties are well established.3.4 This case report focuses on a case of such self-inflicted chemical burn of the oral mucosa reported due to use of clove oil preparation available locally.

\section{CASE REPORT}

A 55 year old female patient reported in Department of Dentistry with a chief complaint of oral ulceration since a day. There was history of repeated toothache for which he applied clove oil on a cotton swab in the mucobuccal fold alongside the tooth. She experienced burning and severe pain due to oil application. On oral examination 48 was carious mesially and was periodontally involved along with clinically missing 46 , and 47. The lesion seen on right buccal mucosa adjacent to 46 to 48 was white and brownish in appearance and had greatest dimensions of $3.5 \times 2.5 \mathrm{~cm}$ (figure 1).

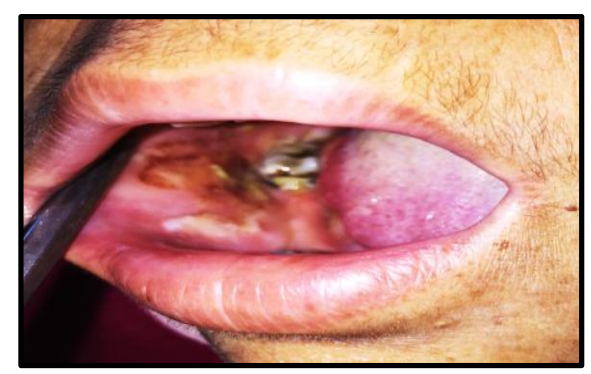

Figure 1. Irregular ulceration on buccal mucosa 
As there were missing 46, 47, the chemical had involved the tongue as well (figure 2). The lesion on tongue involved right lateral surface had whitish appearance and was $3.5 \times 1.5 \mathrm{~cm}$ in greatest dimensions. Both the lesions were shallow and had irregular borders. On palpation, the Lesions were tender. Patient was advised for discontinuation of oil application. The lesions healed slowly over a period of 3 weeks along with application of Triamcinolone acetonide $0.1 \% \mathrm{w} / \mathrm{w}$ ointment twice daily and Benzydamine hydrochloride $0.15 \% \quad \mathrm{w} / \mathrm{v}$ mouthwash which relieved burning.



Figure 2. Ulceration on Tongue

\section{DISCUSSION}

The chemical burns of oral cavity present as whitish lesions covered by pseudomembrane, are irregular in shape and are usually very painful. These burns can cover a large area of oral cavity. If the tissue are contacted for shorter duration cannot lead to necrosis but a shallow lesion with whitish and wrinkled appearance are seen. ${ }^{5}$

In India, the land of Ayurveda and natural medicine, use of medicaments obtained or prepared from plant origin is a great practice especially in rural regions. These extracts from medicinal herbs and plants proven to be therapeutically useful for various ailments have been manufactured by a few local brands as oils or ointments \& easily available over the counter. Many herbal remedies have been used for oral health for hundreds years. ${ }^{6}$ An Ayurvedic specialist's consultation is always required to avoid irrational use of herbal preparations as it can lead to systemic and local effects. The chemical trauma seen in oral cavity is one of the local effect. ${ }^{7}$
These over the counter drugs can have Caustic chemicals which are often very irritating and cause direct trauma to oral mucus memberane. Most commonly used medications such as keeping aspirin directly in vestibular mucosa of carious painful tooth, may result in chemical burn. Iatrogenically, irrigant solutions (sodium hypochlorite or formalin) can irritate the mucosa during endodontic treatment. ${ }^{8}$ However, such injuries are rare since the introduction of rubber dam in dental practice.

Eugenol is the a main ingredient of many dental materials. The oral soft tissue reactions to eugenol can be of three different ways: (1) having adverse effect on fibroblasts and osteoblast-like cells and is cytotoxic at high concentrations hence produces necrosis and reduced healing, ${ }^{9}(2)$ act as a contact allergen leading to localised delayed hypersensitivity reaction in lower concentrations, ${ }^{10}$ and (3) when placed in the mouth, sometimes cause significant generalized allergic reaction. ${ }^{11}$

Prevention is the best treatment of chemical burns of the oral cavity. The iatrogenic chemical burns can be prevented by use of rubber dam. The turnover of oral mucosa is considered very high which results in faster rate of healing in case of superficial burns usually 7 to 14 days. ${ }^{5}$ The antibiotics are needed in very rare cases. The hyaluronic acid gel is considered to help in the healing process. The treatment after chemical injuries, depending upon the severity of lesion, can range from symptomatic topical application of lignocaine, benzydamine, intralesional corticosteroids, caustic acid ingestion, commissuroplasty to mucosal or free radial forearm or free jejunal graft. The surgeries can be done with electrocautery or soft tissue lasers, and wounds are covered by periodontal pack. ${ }^{12}$

\section{CONCLUSIONS AND PRACTICAL IMPLICATIONS}

This case highlights the importance of detailed clinical history to make a final diagnosis and magnitude of educating a patient to prevent future mucosal injury from inappropriate self-treatment. Dentists should include oral chemical burn in diagnosis when a patient has an irregular shallow ulcer or a large necrotic mucosal lesion located near decayed tooth. This understanding can help 
in early recognition of this condition and decreases the probability of overtreatment.

\section{REFERENCES}

1. Dayakar MM, Pai PG, Madhavan SS. Tetracycline hydrochloride chemical burn' as selfinflicted mucogingival injury: a rare case report. Journal of Indian Society of Periodontology 2012;16(2):282-5.

2. Middleton CE, Berwick JE, Adamson DN. Chemical burn in the oral cavity. U.S. Army Medical Department Journal 1995;8:10-2.

3. Hume WR. The pharmacologic and toxicological properties of zinc oxide-eugenol. J Am Dent Assoc. 1986;113(5):789-91.

https://doi.org/10.14219/jada.archive.1986.0256. 4. Newman MG, Hulem C, Colgate J, Anselmo C. Antibacterial susceptibility of plaque bacteria. J Dent Res. 1979;58(7):1722-32. https://doi.org/ 10.1177/00220345790580071401.

5. Greenberg MS, Glick M. Oral Medicine Diagnosis \& Treatment Burket's Tenth Edition. BC

Decker Inc.; 2003

6. Little JW. Complementary and alternative medicine: Impact on dentistry. Oral Surg Oral Pathol Oral Radiol Endod. 2004;98:137-45. https://doi.org/10.1016/j.tripleo.2004.05.011.
7. Shishir RS, Renita C, Kumuda AR, Subhas BG. Irrational use of Eucalyptus oil in dentistry: a case report. Bangladesh Journal of Medical Science 2011; 10(2): 122-4.

8. Ariyawardana A. Traumatic oral mucosal lesions: A mini review and clinical update. Oral Health and Dental Management 2014;13(2):254-9. 9. Rivera C, Droguett D, ArenasMárquez MJ. Oral mucosal lesions in a chilean elderly population: A retrospective study with a systematic review from thirteen countries. Journal of Clinical and Experimental Dentistry 2017;9(2):e276-83.

10. Iegami CM, Tamaki R, Neto PT. A 5-week nonsurgical approach towards denture induced hyperplasia. The Open Dentistry Journal 2017;11:151-4.

11. Vieira-Andrade RG, Zuquim Guimarães Fde F, Vieira Cda S, Freire ST, Ramos-Jorge ML, Fernandes AM. Oral mucosa alterations in a socioeconomically deprived region: Prevalence and associated factors. Brazilian Oral Research 2011;25(5):393-400.

12. Rallan M, Malhotra G, Rallan N, Mayall S. Management of chemical burn in oral cavity. BMJ case reports 2013. https://doi.org/10.1136/bcr-2013009083.

Source of support: Nil, Conflict of interest: None declared 